\title{
Outcomes of endoscopic management of upper tract urothelial carcinoma
}

\author{
John J. Knoedler \\ Division of Urology, Penn State Milton S. Hershey Medical Center, Hershey, PA, USA \\ Correspondence to: John J. Knoedler, MD. Assistant Professor of Surgery, Division of Urology, Penn State Milton S. Hershey Medical Center, 500 \\ University Drive, c4830, Hershey, PA 17033, USA. Email: jknoedler@pennstatehealth.psu.edu.
}

\begin{abstract}
While radical nephroureterectomy (RNU) remains the gold-standard treatment for upper tract urothelial carcinoma (UTUC), a growing volume of literature surrounding endoscopic, organ-sparing procedures has developed over the past few decades. Based on this, endoscopic management of UTUC has gained acceptance as a standard of care approach, particularly among those with low-risk disease or with imperative indications for organ preservation. As a rare disease, however, data is mostly restricted to retrospective single institution series with relatively small numbers. Therefore, comparative outcomes of endoscopic management to RNU remain incompletely defined. Furthermore, the comparative utility of endoscopic approaches (ureteroscopy versus percutaneous resection) and topical therapy following resection lacks prospective analysis. In this article we review the available literature on endoscopic management of UTUC.
\end{abstract}

Keywords: Urothelial carcinoma; upper tract; endoscopic management; organ-sparing surgery

Submitted Nov 26, 2019. Accepted for publication Dec 16, 2019.

doi: $10.21037 /$ tau.2019.12.26

View this article at: http://dx.doi.org/10.21037/tau.2019.12.26

\section{Introduction}

Upper tract urothelial carcinoma (UTUC) is a rare disease, and as such there is a relative lack of high-level evidence regarding its management. The gold-standard remains radical nephroureterectomy (RNU), however experience with organ sparing approaches over the last few decades has carved out a role for endoscopic management. Despite this, understanding both the success and limitations of an organ sparing approach is essential to proper patient selection and counseling. Herein we discuss the outcomes of endoscopic management of UTUC.

\section{Patient selection}

Proper patient selection for endoscopic management is essential, as these tumors carry a high risk of recurrence and accurate grading and staging remains a diagnostic challenge. Ideally, patients undergoing endoscopic management will meet criteria outlined by the EAU guidelines with low-risk disease, defined as unifocal, small $(<2 \mathrm{~cm})$, low-grade by cytology and ureteroscopic biopsy, and without evidence of invasion on computed tomography (1). It is worth noting that the accuracy and inter-observer variability in correctly predicting low grade versus high grade disease based on visual inspection alone is poor (2). Furthermore, the ability to accurately predict tumor grade (much less stage) may be limited, as the study by Wang et al. found that $29 \%$ of patients with endoscopic biopsy of UTUC showing low-grade tumor were found to have high grade disease at the time of RNU (3). In the series by Yamany et al., ureteroscopic biopsy will miss lesions $25 \%$ of the time, and up to $50 \%$ may have missed carcinoma in situ (CIS) (4). Straub et al. found in their series of 77 patients that upper tract cytology and URS biopsy yielded only an $84 \%$ sensitivity for identifying high-grade disease, while $15 \%$ of high-grade tumors at RNU were initially diagnosed as low-grade disease (5). It is therefore essential to make every effort to accurately risk stratify patients and to maintain 
a high index of suspicion when attempts at endoscopic management fail.

While it may be preferable to restrict endoscopic management to well-select patients, imperative indications exist for renal preservation. Imperative or relative indications for a nephron-sparing approach include the presence of an anatomic or functional solitary kidney, bilateral disease, comorbidities disqualifying from RNU, chronic kidney disease, disease states representing a high risk of contralateral recurrence (i.e., Balkan Nephropathy, Lynch Syndrome), or patient refusal to undergo RNU. Among patients with Lynch Syndrome, urothelial carcinoma represents the $3^{\text {rd }}$ most common malignancy after colon and endometrial (6). With a high-risk of recurrence and potential for bilateral disease, these patients may mandate attempt at nephron-sparing surgery.

\section{Endoscopic management versus RNU for UTUC}

Before proceeding, it must be stated that RNU remains the gold-standard management for UTUC. It is important that any urologist embarking on a course of endoscopic management with a patient pause and reflect how the outcome is likely to compare to RNU, and whether that patient would benefit from a more definitive approach. At this time, no high-level comparison of RNU to endoscopic management has been performed. In a 2014 meta-analysis of available studies by Yakoubi and colleagues, they identified 8 studies which were all retrospective or non-randomized studies comparing RNU to endoscopic management (7). They derived pooled data of 1,002 patients, including 322 who underwent an endoscopic approach and 680 who underwent RNU. There was no significant difference with respect to cancer-specific or overall survival between to the two treatment approaches. However, with retrospective, low-level data, and a high degree of heterogeneity, it is difficult to draw an accurate comparison between the two treatment modalities. Based on this, the authors note that equivalence of organ-sparing endoscopic management and RNU are not well established in this meta-analysis. As patients undergoing endoscopic management are either highly selected or with imperative indications, drawing accurate head-to-head comparisons with RNU will likely be impossible without prospective trials. However, it is encouraging to those pursing endoscopic management that survival appears not to be grossly inferior, and may be equivalent to RNU.

\section{Ureteroscopic versus percutaneous tumor resection}

The optimal approach for endoscopic management remains dependent on the specific patient, as well as surgeon preference and experience. Studies reporting on retrograde or percutaneous endoscopic management are in Table 1. Ureteroscopy is generally accepted as the initial diagnostic and treatment modality of choice, as it offers a minimally invasive approach with low morbidity to obtain visual and pathologic diagnosis, which may be used to risk stratify patients. For smaller tumors amenable to ablation, ureteroscopy is usually the preferred approach. It allows for visual interpretation, cytology via barbotage, biopsy, and primary tumor ablation while maintaining integrity of the urinary tract. Recently, Scotland et al. published a 23-year experience of ureteroscopy for management of low-grade UTUC with tumors $>2 \mathrm{~cm}$ in size (8). Among 80 patients with a median follow up over 43 months, they found that $90.5 \%$ of tumors recurred, with $31.7 \%$ progressing in tumor grade and $20 \%$ undergoing RNU. Overall and cancer specific survival was $75 \%$ and $84 \%$ respectively at 5 years. This study demonstrates that ureteroscopic management may be effective, even for larger tumors, with acceptable survival rates. However it is important to note that their recurrence rate is quite high $(90 \%)$ and patients undergoing a primary ureteroscopic approach need close and vigilant follow up and surveillance, whether managing small or large lesions.

Smith et al. reported the first experience with percutaneous tumor resection in 1987 (31) and since then multiple authors have reported on its efficacy $(19,23,26,28,32-34)$. In the largest series to date, Motamedinia and colleagues reported their 30-year experience of percutaneous resection of UTUC in 141 patients. With a median follow up of 66 months, they found that disease recurred in $37 \%$ of low-grade tumors and $63 \%$ of high-grade tumors, and that ultimately $13 \%$ of patients progressed to RNU. Of note in their series, the longest time to recurrence was 116 months, making the case for indefinite longitudinal follow up of these patients.

Cutress and colleagues performed a systematic review of ureteroscopic and percutaneous management of UTUC (32). A total of 56 manuscript met criteria for analysis. The found a cancer specific survival of $98 \%$ for low grade disease treated endoscopically by either approach. However there was a marked difference in recurrence 
Table 1 Outcomes of endoscopic management for upper tract urothelial carcinoma with long-term follow up

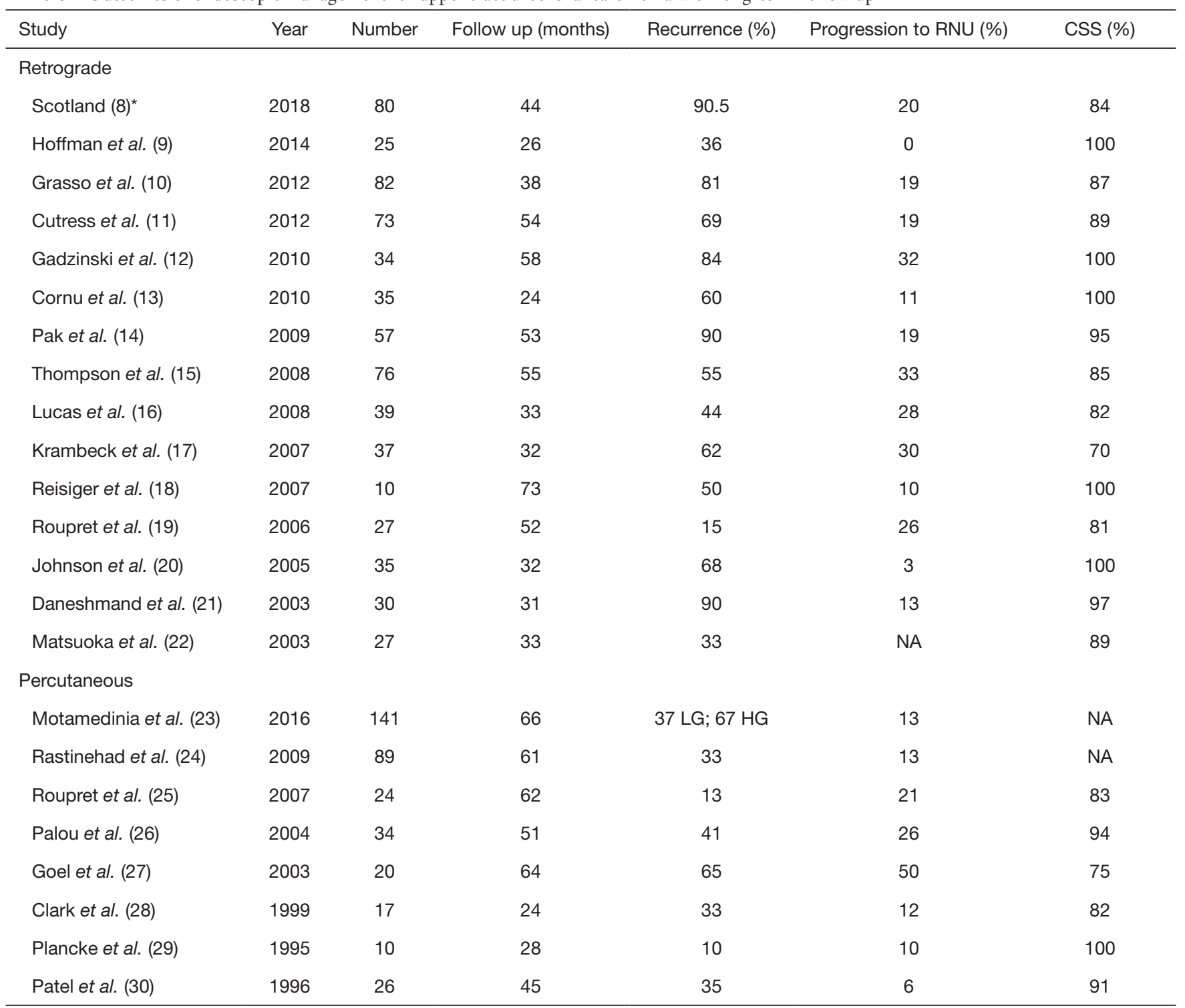

*, this series was restricted to ureteroscopic management of tumors $>2 \mathrm{~cm}$ in size. RNU, radical nephroureterectomy; CSS, cancer specific survival; LG, low grade; HG, high grade, NA, not available.

rates between ureteroscopic and percutaneous approaches. For low-grade disease, URS resulted in a $52 \%$ recurrence compared to $23 \%$ for percutaneous. Among high-grade tumors recurrence rose to $76 \%$ for URS and $40 \%$ for percutaneous tumor resection. It is also worth examining the complications observed between these two cohorts. Among patients electing for ureteroscopy, $14 \%$ experienced complications with a significant stricture rate of $11 \%$. In comparison, the pooled complication rate for percutaneous resection was $27 \%$, with a $17 \%$ risk of blood transfusion,
$2 \%$ risk of renal failure, $1 \%$ risk of emergency RNU or renal artery embolization for hemorrhage, and a $0.3 \%$ risk of percutaneous tract tumor seeding. Taken in totality, this analysis demonstrates the balance the urologist and patient must weigh in management. Percutaneous access allows for a more direct path to the tumor, and utilization of larger and more thorough instrumentation (Figure 1). As such, percutaneous resection offers a decreased risk of recurrence with comparatively higher risk of complications, including Clavien-Dindo high grade complications. This 

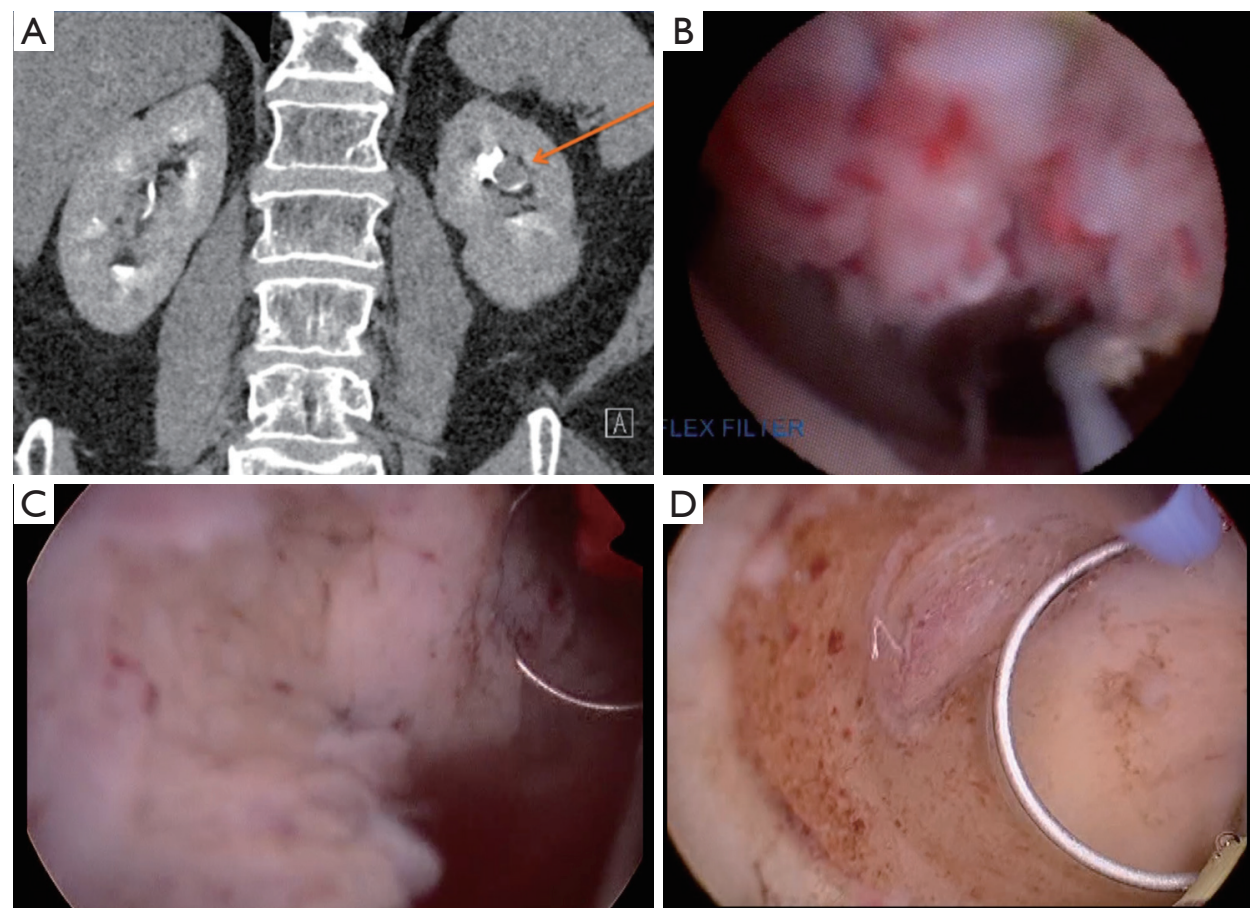

Figures 1 Left upper pole tumor in a patient with a history of cystectomy and ileal conduit urinary diversion for muscle-invasive bladder cancer. (A) Coronal CT with arrow showing upper pole tumor; (B) low-grade upper tract urothelial carcinoma seen through percutaneous approach, prior to resection; (C) percutaneous bi-polar resection of upper tract tumor; (D) complete visual resection of all tumor.

is not insignificant given that many patients undergoing endoscopic management are often more comorbid and with less reserve. However the morbidity of percutaneous resection is typically less than with RNU, and therefore the higher odds of rendering a patient disease free with a percutaneous (versus ureteroscopic) approach may be justified to avoid more radical surgery. Therefore careful patient counseling is imperative, and patients should play an important role in treatment selection.

Of concern with endoscopic management is the risk of tumor seeding. As mentioned previously, the risk of tumor tract seeding at the time of percutaneous resection is low at $<1 \%$ (32). While patients must be counselled on this risk, it does not present a significant barrier to treatment. In comparison, there is concern that URS may offer an increased risk of bladder seeding and intravesical tumor recurrence with conflicting data. Multiple studies have reported an increased risk of bladder recurrence following ureteroscopy for UTUC (35). Ishikawa et al. reported their series of patients undergoing RNU for UTUC, and found that prior diagnostic URS did not increase the risk of subsequent bladder tumor (36). Similarly, Baboudjian et al. reported their series of 171 patients who underwent $\mathrm{RNU}$, and found that prior URS was an independent predictor of bladder recurrence with an $[\mathrm{OR}=4(1.4-11.9)$, $\mathrm{P}=0.01]$ (37). Recently, Lee and colleagues reported their experience of 502 patients undergoing RNU, of whom $206(41 \%)$ underwent prior URS and 296 (59\%) did not have a pre-RNU URS (38). Among these two groups they found no difference in the risk of bladder recurrence. In the most robust data to date, a 2017 meta-analysis of 6 studies reporting bladder recurrence rates among patients undergoing URS prior to RNU found on pooled analysis a statistically significant increased risk of bladder recurrence (HR 1.56, 95\% CI: 1.33-1.88; $\mathrm{P}<0.001)$. Given the accepted role of intravesical chemotherapy at the time of RNU, there is growing opinion that there may be a role in the setting of endoscopic management of UTUC. However additional studies are needed in this area.

\section{Upper tract recurrence following radical cystectomy}

Upper tract recurrence of urothelial carcinoma represents 
a particular diagnostic and therapeutic challenge. In a 2012 meta-analysis, the prevalence of upper tract recurrence following radical cystectomy ranged from $0.75-6.4 \%$ (39). Krambeck et al. reported their series of 90 patients with a history of primary bladder cancer who subsequently recurred in the upper tract and were treated endoscopically (17). Among this cohort, patients with previous radical cystectomy were at increased risk of death from disease (RR 3.34). Therefore it is essential to establish an accurate and timely diagnosis in these patients. Our practice is to establish retrograde access for diagnosis if possible, which is more often successful in the case of ileal conduit urinary diversion. In the case of neobladder, access to the upper tract can be challenging due to issues navigating the tortuosity of the afferent limb. In one series involving attempted access to 17 renal units, successful access was achieved $59 \%$ of the time, and a learning curve was seen throughout the series (40). When unable to access the upper tract retrograde, a percutaneous antegrade approach is required.

\section{Surveillance following endoscopic management}

With recurrence following RNU common, close surveillance following endoscopically managed UTUC is essential. Superficial tumors may continue to be managed endoscopically, but approximately $20-30 \%$ of patients will progress to RNU $(11,15,32)$. Currently, EAU guidelines indicate that, following an organ sparing approach, patients should be followed to 5 years or beyond (41). This should include CT urogram at 3 months, 6 months, and then yearly, as well as cystoscopy with ureteroscopy and in situ cytology at 3 months, 6 months, and then every 6 months until 2 years then yearly. This algorithm, while thorough, places a high burden on the patient. Among a population that is typically older and comorbid, the frequency anesthetics required for ureteroscopy may be difficult or impossible.

In our practice, at least one endoscopic surveillance is typically performed within 3 months. Villa et al., in a novel study, examined the role of early repeat ureteroscopy at 6 weeks and found that the presence of tumor was associated with poor subsequent recurrence free rates (42). One wonders whether these represent early recurrence or inadequate resection of tumor, but nonetheless presence of disease during early surveillance may be associated with treatment failure. Following the initial early surveillance, attempts are made to space out anesthetic procedures more quickly to 6- or 12-month intervals, particularly amongst patients with low-grade disease while using cross sectional imaging in the interim (CT or MR Urogram). Particularly comorbid patients may be followed with serial cross sectional imaging alone following an initial early surveillance, choosing only to intervene on suspicious findings. This approach is chosen via shared decision making with the patient. Given that up to $50 \%$ of patients with upper tract tumors will eventually recur within the bladder, we will typically perform cystoscopy at 3, 6, 12 months and then yearly.

\section{Intracavitary therapy}

With ample evidence to support the use of intracavitary therapy for urothelial carcinoma of the bladder, it is a logical extension to apply these therapies to the upper tract. However outcomes are diminished, and the evidence in support of topical therapy for UTUC more limited. While BCG is the most common topical agent used, studies have also described the use of Mitomycin C (27,43-46), epirubicin (27), thiotepa (44,46), Adriamycin (47), and BCG with Interferon $(44,48)$.

Topical intracavitary therapy for UTUC may be broken into that used for curative with CIS, and adjuvant therapy for $\mathrm{Ta} / \mathrm{T} 1$ disease. Studies breaking down the utilization for topical therapy for curative and adjuvant intent are reported in Tables 2 and 3 respectively. Response rates for CIS are typically defined as negative cytology, and range from 60 $100 \%$. In comparison, BCG for adjuvant treatment of Ta/ T1 disease shows a much lower initial response. Rastinehad et al. reported the largest series of BCG for adjuvant treatment of UTUC to date among a cohort of 89 total renal units undergoing percutaneous resection of upper tract tumor among whom 50 received BCG (24). When compared, there was no difference between those who did and did not receive BCG with regards to recurrence, time to recurrence or progression and the authors therefore call into question the utility of BCG in the adjuvant setting.

A recent 2019 meta-analysis of topical therapy for UTUC examined pooled data 27 reports including 438 patients, and 18 studies eligible for quantitative analysis (64). All studies identified were case series, as to date no prospective randomized studies have been presented. Patients were broken into two groups, including Ta/T1 (adjuvant) tumors and CIS (curative). Among patients with $\mathrm{Ta} / \mathrm{T} 1$ disease, pooled estimates showed $40 \%$ recurred, 94\% cancer-specific survival, and $71 \%$ overall survival. There was no difference found between treatment regimens or method of instillation. In comparison topical therapy for 
Table 2 Series reporting upper tract instillation for CIS with curative intent

\begin{tabular}{|c|c|c|c|c|c|c|}
\hline Study & Renal units & Agent & Route & Mean follow up (months) & Response (\%) & Recurrence (\%) \\
\hline Yokogi et al. (50) (1996) & 8 & $\mathrm{BCG}$ & Both & $10-46^{*}$ & 63 & 0 \\
\hline Nishino et al. (51) (2000) & 6 & $\mathrm{BCG}$ & Retrograde & 22 & 100 & 0 \\
\hline Nonomura et al. (52) (2000) & 11 & $\mathrm{BCG}$ & Retrograde & NA & 82 & 22 \\
\hline Thalmann et al. (54) (2002) & 25 & $\mathrm{BCG}$ & Antegrade & 42 & 88 & 55 \\
\hline Irie et al. (55) (2002) & 13 & $\mathrm{BCG}$ & Retrograde & 36 & 100 & 11 \\
\hline Miyake et al. (56) (2002) & 16 & BCG & Both & 30 & 81 & 19 \\
\hline Hayashida et al. (57) (2004) & 11 & $\mathrm{BCG}$ & Both & 51 & 100 & 50 \\
\hline
\end{tabular}

*, no mean reported, range given. CIS, carcinoma in situ; BCG, bacillus calmette guerin.

Table 3 Series reporting adjuvant upper tract instillations for $\mathrm{Ta} / \mathrm{T} 1$ disease

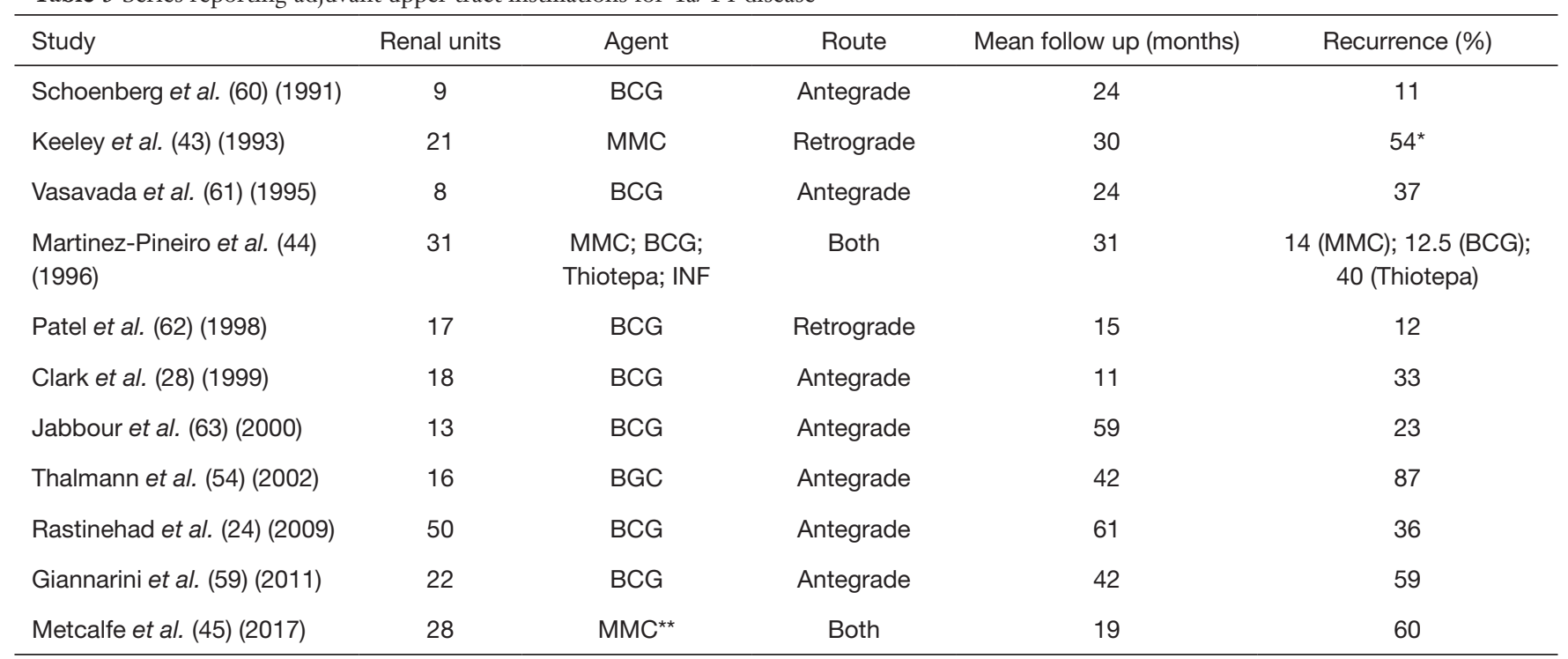

${ }^{*}$, of $58 \%$ of patients were disease free after initial treatment, and of those $54 \%$ recurred; ${ }^{*}$, included induction and maintenance therapy for $\mathrm{Ta} / \mathrm{T} 1$ disease. BCG, bacillus calmette guerin; MMC, mitomycin C; INF, interferon.

CIS $84 \%$ had response based on cytology, 34\% experienced upper tract recurrence, and $16 \%$ progressed. Again, treatment regimen did not influence response. The authors concluded that recurrence rates closely match those of patients managed by an organ-sparing approach followed by observation, and therefore little evidence in favor topical therapy for UTUC exists. While many urologists may, nonetheless, feel pressed to attempt topical therapy as an attempt to exhaust all options in an effort to avoid RNU in patients for whom such a surgery is prohibitive, the outcomes reported thus for do not inspire confidence and newer treatments are needed.

A major barrier to effective topical therapy for UTUC is the issue of dwell time: instillations in the upper tract 
drain and prevent effective contact be agent of choice and the site of therapy. In an attempt to address the treatment failure of topical therapy for UTUC, recent innovations for drug delivery are under investigation. Barros et al. reported on a novel biodegradable stent impregnated with supercritical $\mathrm{CO}_{2}$ with chemotherapeutic drugs, such as paclitaxel, epirubicin, doxorubicin, and gemcitabine (65). Cancer cell lines exposed to the anti-cancer biodegradable stents showed a $75 \%$ reduction in viability at 72 hours. This offers the potential of a procedure familiar to all urologists (stent placement) as a means to provide effective topical therapy to patients with UTUC. An additional developing treatment is a thermo-polymer gel compounded with Mitomycin C (UGN-101), which forms a liquid when cooled and a gel cast at body temperature, thereby allowing for improved dwell time in the upper tract. Two clinical trials are underway for the use of this compounded gel at ablating low-grade tumors in UTUC (NCT02793128) and non-muscle invasive bladder cancer (NCT03558503). Initial results of the UTUC trial (NCT02793128) presented at the American Urologic Association Annual Meeting 2019 demonstrated promise. In a cohort of patients with residual disease low-grade disease within the kidney following initial diagnostic evaluation, $60 \%$ achieved complete response following chemoablation with UGN-101.

\section{Conclusions}

While there exists a clear role for endoscopic management of UTUC, its role in management continues to evolve. Available retrospective data shows acceptable cancer specific survival among appropriately selected patients. While an organ sparing approach avoids radical surgery (and the associated risks), it comes at the cost of repetitive surveillance often under anesthesia and the high rate of local recurrence. Thus far, no approved topical therapies have proven highly effective at decrease recurrence rates with upper tract instillation of BCG and topical chemotherapy showing some benefit to CIS but little clear role in $\mathrm{Ta} / \mathrm{T} 1$ disease. With new therapies on the horizon, it is hopeful that improved delivery of topical therapy to the upper tract will expand our utilization and effectiveness of endoscopically managed UTUC.

\section{Acknowledgments}

Funding: None.

\section{Footnote}

Provenance and Peer Review: This article was commissioned by the Guest Editors (John J. Knoedler and Jay D. Raman) for the series "Upper-Tract Urothelial Carcinoma: Current State and Future Directions" published in Translational Andrology and Urology. The article was sent for external peer review organized by the Guest Editors and the editorial office.

Conflicts of Interest: The series "Upper-Tract Urothelial Carcinoma: Current State and Future Directions" was commissioned by the editorial office without any funding or sponsorship. JJK served as the unpaid Guest Editor for the series. The author has no other conflicts of interest to declare.

Ethical Statement: The author is accountable for all aspects of the work in ensuring that questions related to the accuracy or integrity of any part of the work are appropriately investigated and resolved.

Open Access Statement: This is an Open Access article distributed in accordance with the Creative Commons Attribution-NonCommercial-NoDerivs 4.0 International License (CC BY-NC-ND 4.0), which permits the noncommercial replication and distribution of the article with the strict proviso that no changes or edits are made and the original work is properly cited (including links to both the formal publication through the relevant DOI and the license). See: https://creativecommons.org/licenses/by-nc-nd/4.0/.

\section{References}

1. Rouprêt M, Babjuk M, Comperat E, et al. European Association of Urology Guidelines on Upper Urinary Tract Urothelial Carcinoma: 2017 Update. Eur Urol 2018;73:111-22.

2. Freund JE, Legemate JD, Baard J, et al. Upper Tract Urothelial Carcinoma Grade Prediction Based on the Ureteroscopic Appearance: Caution Should be Taken. Urology 2019;132:69-74.

3. Wang JK, Tollefson MK, Krambeck AE, et al. High rate of pathologic upgrading at nephroureterectomy for upper tract urothelial carcinoma. Urology 2012;79:615-9.

4. Yamany T, van Batavia J, Ahn J, et al. Ureterorenoscopy for upper tract urothelial carcinoma: how often are we 
missing lesions? Urology 2015;85:311-5.

5. Straub J, Strittmatter F, Karl A, et al. Ureterorenoscopic biopsy and urinary cytology according to the 2004 WHO classification underestimate tumor grading in upper urinary tract urothelial carcinoma. Urol Oncol 2013;31:1166-70.

6. Rouprêt M, Yates DR, Comperat E, et al. Upper urinary tract urothelial cell carcinomas and other urological malignancies involved in the hereditary nonpolyposis colorectal cancer (lynch syndrome) tumor spectrum. Eur Urol 2008;54:1226-36.

7. Yakoubi R, Colin P, Seisen T, et al. Radical nephroureterectomy versus endoscopic procedures for the treatment of localised upper tract urothelial carcinoma: a meta-analysis and a systematic review of current evidence from comparative studies. Eur J Surg Oncol 2014;40:1629-34.

8. Scotland KB, Kleinmann N, Cason D, et al. Ureteroscopic Management of Large $>/=2 \mathrm{~cm}$ Upper Tract Urothelial Carcinoma: A Comprehensive 23-Year Experience. Urology 2018;121:66-73.

9. Hoffman A, Yossepowitch O, Erlich Y, et al. Oncologic results of nephron sparing endoscopic approach for upper tract low grade transitional cell carcinoma in comparison to nephroureterectomy - a case control study. BMC Urol 2014;14:97.

10. Grasso M, Fishman AI, Cohen J, et al. Ureteroscopic and extirpative treatment of upper urinary tract urothelial carcinoma: a 15-year comprehensive review of 160 consecutive patients. BJU Int 2012;110:1618-26.

11. Cutress ML, Stewart GD, Wells-Cole S, et al. Longterm endoscopic management of upper tract urothelial carcinoma: 20-year single-centre experience. BJU Int 2012;110:1608-17.

12. Gadzinski AJ, Roberts WW, Faerber GJ, et al. Longterm outcomes of nephroureterectomy versus endoscopic management for upper tract urothelial carcinoma. J Urol 2010;183:2148-53.

13. Cornu JN, Rouprêt M, Carpentier X, et al. Oncologic control obtained after exclusive flexible ureteroscopic management of upper urinary tract urothelial cell carcinoma. World J Urol 2010;28:151-6.

14. Pak RW, Moskowitz EJ, Bagley DH. What is the cost of maintaining a kidney in upper-tract transitional-cell carcinoma? An objective analysis of cost and survival. J Endourol 2009;23:341-6.

15. Thompson RH, Krambeck AE, Lohse CM, et al. Endoscopic management of upper tract transitional cell carcinoma in patients with normal contralateral kidneys. Urology 2008;71:713-7.

16. Lucas SM, Svatek RS, Olgin G, et al. Conservative management in selected patients with upper tract urothelial carcinoma compares favourably with early radical surgery. BJU Int 2008;102(2):172-6.

17. Krambeck AE, Thompson RH, Lohse CM, et al. Endoscopic management of upper tract urothelial carcinoma in patients with a history of bladder urothelial carcinoma. J Urol 2007;177:1721-6.

18. Reisiger K, Hruby G, Clayman RV, et al. Office-based surveillance ureteroscopy after endoscopic treatment of transitional cell carcinoma: technique and clinical outcome. Urology 2007;70:263-6.

19. Rouprêt M, Hupertan V, Traxer O, et al. Comparison of open nephroureterectomy and ureteroscopic and percutaneous management of upper urinary tract transitional cell carcinoma. Urology 2006;67:1181-7.

20. Johnson GB, Fraiman M, Grasso M. Broadening experience with the retrograde endoscopic management of upper urinary tract urothelial malignancies. BJU Int 2005;95 Suppl 2:110-3.

21. Daneshmand S, Quek ML, Huffman JL. Endoscopic management of upper urinary tract transitional cell carcinoma: long-term experience. Cancer 2003;98:55-60.

22. Matsuoka K, Lida S, Tomiyasu K, et al. Transurethral endoscopic treatment of upper urinary tract tumors using a holmium:YAG laser. Lasers Surg Med 2003;32:336-40.

23. Motamedinia P, Keheila M, Leavitt DA, et al. The Expanded Use of Percutaneous Resection for Upper Tract Urothelial Carcinoma: A 30-Year Comprehensive Experience. J Endourol 2016;30:262-7.

24. Rastinehad AR, Ost MC, Vanderbrink BA, et al. A 20year experience with percutaneous resection of upper tract transitional carcinoma: is there an oncologic benefit with adjuvant bacillus Calmette Guerin therapy? Urology 2009;73:27-31.

25. Rouprêt $M$, Traxer O, Tligui $M$, et al. Upper urinary tract transitional cell carcinoma: recurrence rate after percutaneous endoscopic resection. Eur Urol 2007;51:70913; discussion 714.

26. Palou J, Piovesan LF, Huguet J, et al. Percutaneous nephroscopic management of upper urinary tract transitional cell carcinoma: recurrence and long-term followup. J Urol 2004;172:66-9.

27. Goel MC, Mahendra V, Roberts JG. Percutaneous management of renal pelvic urothelial tumors: long-term followup. J Urol 2003;169:925-9; discussion 9-30. 
28. Clark PE, Streem SB, Geisinger MA. 13-year experience with percutaneous management of upper tract transitional cell carcinoma. J Urol 1999;161:772-5; discussion 775-6.

29. Plancke HR, Strijbos WE, Delaere KP. Percutaneous endoscopic treatment of urothelial tumours of the renal pelvis. Br J Urol 1995;75(6):736-9.

30. Patel A, Soonawalla P, Shepherd SF, et al. Long-term outcome after percutaneous treatment of transitional cell carcinoma of the renal pelvis. J Urol 1996;155:868-74.

31. Smith AD, Orihuela E, Crowley AR. Percutaneous management of renal pelvic tumors: a treatment option in selected cases. J Urol 1987;137:852-6.

32. Cutress ML, Stewart GD, Zakikhani P, et al. Ureteroscopic and percutaneous management of upper tract urothelial carcinoma (UTUC): systematic review. BJU Int 2012;110:614-28.

33. Lee BR, Jabbour ME, Marshall FF, et al. 13-year survival comparison of percutaneous and open nephroureterectomy approaches for management of transitional cell carcinoma of renal collecting system: equivalent outcomes. J Endourol 1999;13:289-94.

34. Jarrett TW, Sweetser PM, Weiss GH, et al. Percutaneous management of transitional cell carcinoma of the renal collecting system: 9-year experience. J Urol 1995;154:1629-35.

35. Liu P, Su XH, Xiong GY, et al. Diagnostic Ureteroscopy for Upper Tract Urothelial Carcinoma is Independently Associated with Intravesical Recurrence after Radical Nephroureterectomy. Int Braz J Urol 2016;42:1129-35.

36. Ishikawa $\mathrm{S}$, Abe $\mathrm{T}$, Shinohara $\mathrm{N}$, et al. Impact of diagnostic ureteroscopy on intravesical recurrence and survival in patients with urothelial carcinoma of the upper urinary tract. J Urol 2010;184:883-7.

37. Baboudjian M, Al-Balushi K, Michel F, et al. Diagnostic ureteroscopy prior to nephroureterectomy for urothelial carcinoma is associated with a high risk of bladder recurrence despite technical precautions to avoid tumor spillage. World J Urol 2020;38:159-65.

38. Lee HY, Yeh HC, Wu WJ, et al. The diagnostic ureteroscopy before radical nephroureterectomy in upper urinary tract urothelial carcinoma is not associated with higher intravesical recurrence. World J Surg Oncol 2018;16:135.

39. Picozzi S, Ricci C, Gaeta M, et al. Upper urinary tract recurrence following radical cystectomy for bladder cancer: a meta-analysis on 13,185 patients. J Urol 2012;188:2046-54.

40. Rivera M, Krambeck A. Retrograde ureteroscopy via a continent urinary diversion: surgical techniques and common pitfalls. J Endourol 2014;28:763-6.

41. Rouprêt M, Babjuk M, Comperat E, et al. European Association of Urology Guidelines on Upper Urinary Tract Urothelial Cell Carcinoma: 2015 Update. Eur Urol 2015;68:868-79.

42. Villa L, Cloutier J, Letendre J, et al. Early repeated ureteroscopy within 6-8 weeks after a primary endoscopic treatment in patients with upper tract urothelial cell carcinoma: preliminary findings. World J Urol 2016;34:1201-6.

43. Keeley FX Jr, Bagley DH. Adjuvant mitomycin C following endoscopic treatment of upper tract transitional cell carcinoma. J Urol 1997;158:2074-7.

44. Martínez-Piñeiro JA, Garcia Matres MJ, Martinez-Pineiro L. Endourological treatment of upper tract urothelial carcinomas: analysis of a series of 59 tumors. J Urol 1996;156:377-85.

45. Metcalfe M, Wagenheim G, Xiao L, et al. Induction and Maintenance Adjuvant Mitomycin C Topical Therapy for Upper Tract Urothelial Carcinoma: Tolerability and Intermediate Term Outcomes. J Endourol 2017;31:946-53.

46. Elliott DS, Blute ML, Patterson DE, et al. Long-term follow-up of endoscopically treated upper urinary tract transitional cell carcinoma. Urology 1996;47:819-25.

47. See WA. Continuous antegrade infusion of adriamycin as adjuvant therapy for upper tract urothelial malignancies. Urology 2000;56:216-22.

48. Katz MH, Lee MW, Gupta M. Setting a new standard for topical therapy of upper-tract transitional-cell carcinoma: BCG and interferon-alpha2B. J Endourol 2007;21:374-7; discussion 377.

49. Sharpe JR, Duffy G, Chin JL. Intrarenal bacillus CalmetteGuerin therapy for upper urinary tract carcinoma in situ. J Urol 1993;149:457-9; discussion 459-60.

50. Yokogi H, Wada Y, Mizutani M, et al. Bacillus CalmetteGuerin perfusion therapy for carcinoma in situ of the upper urinary tract. Br J Urol 1996;77:676-9.

51. Nishino Y, Yamamoto N, Komeda H, et al. Bacillus Calmette-Guérin instillation treatment for carcinoma in situ of the upper urinary tract. BJU Int 2000;85:799-801.

52. Nonomura N, Ono Y, Nozawa M, et al. Bacillus CalmetteGuerin perfusion therapy for the treatment of transitional cell carcinoma in situ of the upper urinary tract. Eur Urol 2000;38:701-4; discussion 705.

53. Okubo K, Ichioka K, Terada N, et al. Intrarenal bacillus Calmette-Guerin therapy for carcinoma in situ of the upper urinary tract: long-term follow-up and natural 
course in cases of failure. BJU Int 2001;88:343-7.

54. Thalmann GN, Markwalder R, Walter B, et al. Longterm experience with bacillus Calmette-Guerin therapy of upper urinary tract transitional cell carcinoma in patients not eligible for surgery. J Urol 2002;168:1381-5.

55. Irie A, Iwamura $M$, Kadowaki K, et al. Intravesical instillation of bacille Calmette-Guerin for carcinoma in situ of the urothelium involving the upper urinary tract using vesicoureteral reflux created by a double-pigtail catheter. Urology 2002;59:53-7.

56. Miyake H, Eto H, Hara S, et al. Clinical outcome of bacillus Calmette-Guerin perfusion therapy for carcinoma in situ of the upper urinary tract. Int J Urol 2002;9:677-80.

57. Hayashida Y, Nomata K, Noguchi M, et al. Long-term effects of bacille Calmette-Guerin perfusion therapy for treatment of transitional cell carcinoma in situ of upper urinary tract. Urology 2004;63:1084-8.

58. Kojima Y, Tozawa K, Kawai N, et al. Long-term outcome of upper urinary tract carcinoma in situ: effectiveness of nephroureterectomy versus bacillus Calmette-Guerin therapy. Int J Urol 2006;13:340-4.

59. Giannarini G, Kessler TM, Birkhauser FD, et al. Antegrade perfusion with bacillus Calmette-Guerin in patients with non-muscle-invasive urothelial carcinoma

Cite this article as: Knoedler JJ. Outcomes of endoscopic management of upper tract urothelial carcinoma. Transl Androl Urol 2020;9(4):1821-1830. doi: 10.21037/tau.2019.12.26 of the upper urinary tract: who may benefit? Eur Urol 2011;60:955-60.

60. Schoenberg MP, Van Arsdalen KN, Wein AJ. The management of transitional cell carcinoma in solitary renal units. J Urol 1991;146:700-2; discussion 702-3.

61. Vasavada SP, Streem SB, Novick AC. Definitive tumor resection and percutaneous bacille Calmette-Guerin for management of renal pelvic transitional cell carcinoma in solitary kidneys. Urology 1995;45:381-6.

62. Patel A, Fuchs GJ. New techniques for the administration of topical adjuvant therapy after endoscopic ablation of upper urinary tract transitional cell carcinoma. J Urol 1998;159:71-5.

63. Jabbour ME, Smith AD. Primary percutaneous approach to upper urinary tract transitional cell carcinoma. Urol Clin North Am 2000;27:739-50.

64. Foerster B, D'Andrea D, Abufaraj M, et al. Endocavitary treatment for upper tract urothelial carcinoma: A meta-analysis of the current literature. Urol Oncol 2019;37:430-6.

65. Barros AA, Browne S, Oliveira C, et al. Drug-eluting biodegradable ureteral stent: New approach for urothelial tumors of upper urinary tract cancer. Int J Pharm 2016;513:227-37. 